\title{
A case of macro-TSH consisting of IgA-bound TSH
}

\author{
Miho Fukushita ${ }^{1)}$, Natsuko Watanabe ${ }^{1)}$, Jaeduk Yoshimura Noh ${ }^{1)}$, Ai Yoshihara' ${ }^{1)}$, Masako Matsumoto ${ }^{1)}$, \\ Nami Suzuki ${ }^{1)}$, Ran Yoshimura ${ }^{1)}$, Kiminori Sugino ${ }^{2)}$ and Koichi Ito ${ }^{2)}$ \\ 1) Department of Internal Medicine, Ito Hospital, Tokyo, Japan \\ 2) Department of Surgery, Ito Hospital, Tokyo, Japan
}

\begin{abstract}
An asymptomatic, 68-year-old Japanese man visited our hospital for further examination of subclinical hypothyroidism. At the first visit, the serum TSH level was markedly elevated $(36.6 \mu \mathrm{IU} / \mathrm{mL})$, but the serum level of free T4 was within the reference interval. Thyroid dysfunction due to dietary iodine excess was initially suspected. However, even after iodine restriction, his thyroid function tests were the same as at the first visit, which suggested false elevation of the TSH level. The TSH levels were compared among three different measurement systems, which showed a similar tendency of TSH elevation above the reference interval, but the different TSH elevation levels among the measurement methods suggested the existence of some interfering substance. Neither serial dilution of the patient's serum nor polyethylene glycol and protein G precipitation tests showed any significant changes in the recovery rate. IgG-bound macro-TSH was ruled out. The TSH peak on gel filtration chromatography was located at a molecular size greater than IgA, which suggested the presence of IgA-bound TSH. After precipitation with Jacalin, which binds specifically to IgA, the TSH level decreased from $30.7 \mu \mathrm{IU} / \mathrm{mL}$ to $2.01 \mu \mathrm{IU} / \mathrm{mL}$, within the reference interval. Thus, IgA-bound macro-TSH was identified. Macro-TSH is a rare condition in which an immunoglobulin-bound, high-molecular-weight form of TSH results in a false elevation of the serum TSH level. When there is a discrepancy between the results of thyroid function tests and clinical symptoms, and macro-TSH is suspected, it is necessary to know that not only IgG-bound TSH but also IgA-bound TSH could be the cause.
\end{abstract}

Key words: Macro-TSH, IgA, Gel filtration chromatography, Jacalin, Subclinical hypothyroidism

SUBCLINICAL HYPOTHYROIDISM is a common clinical entity found in $4-20 \%$ of the adult population; it is defined as a high TSH level with free T3 (fT3) and free T4 (fT4) levels in the reference interval [1]. Subclinical hypothyroidism should be treated with caution because of the possibility of transient thyroid dysfunction that does not require treatment, such as transient effects due to the convalescence phase of painless thyroiditis, excess iodine from a diet rich in iodine [2,3], or, in rare cases, false elevation of serum TSH levels due to measurement interference [4].

Macro-TSH is a rare condition in which an immunoglobulin-bound, high-molecular-weight form of TSH results in false elevation of the serum TSH level. The possibility of interference in thyroid function tests is usually identified by additional laboratory tests, such as comparison of assay methods, dilution procedures, precipitation tests, and gel filtration chromatography

Submitted Jan. 8, 2021; Accepted Apr. 29, 2021 as EJ21-0021 Released online in J-STAGE as advance publication May 25, 2021 Correspondence to: Miho Fukushita, Department of Internal Medicine, Ito Hospital, 4-3-6 Jingumae, Shibuya-ku, Tokyo 150-8308, Japan.

E-mail: miho-suzuki@ito-hospital.jp when needed $[4,5]$.

Hattori et al. reported their evaluation of 681 consecutive patients with elevated TSH concentrations with fT4 levels in the reference interval [6]. Of these, 10 patients $(1.5 \%)$ were diagnosed with macro-TSH, which included eight with anti-TSH autoantibodies of the IgG class and two with non-IgG antibodies. The binding of IgG to TSH has been reported as the main cause of macro-TSH $[4,7$, $8]$, but whether other immunoglobulin isotypes are involved remains unclear. The first case of a macro-TSH consisting of IgA-bound TSH is reported.

\section{Case Presentation}

A 68-year-old Japanese man was found to have subclinical hypothyroidism (fT3 $2.66 \mathrm{pg} / \mathrm{mL}, \quad$ fT4 $1.31 \mathrm{ng} / \mathrm{dL}$, TSH $40.0 \mu \mathrm{IU} / \mathrm{mL}$ ) (Table 1 , column A) and an incidental thyroid nodule on carotid artery ultrasonography at a regular clinic visit. At the age of 66 years, he was diagnosed with angina pectoris and underwent percutaneous coronary intervention. His medical history also included diabetes mellitus, dyslipidemia, prostatic hyperplasia, and allergies, and he was taking the following medications regularly: low doses of aspirin 
for angina, sitagliptin for diabetes mellitus, rosuvastatin for dyslipidemia, naftopidil (selective $\alpha 1$-adrenoceptor antagonist) for prostatic hyperplasia, and olopatadine (anti-allergic agent) for urticaria. He had no family history of thyroid disease and did not smoke, but he regularly ate salted kelp, tsukudani (a Japanese food based on kelp), and kelp candy. He was allergic to iodine contrast agents.

One month later, at his first visit to our hospital, there were no signs or symptoms of thyroid dysfunction. He was $170 \mathrm{~cm}$ tall, weighed $75 \mathrm{~kg}$, had a heart rate of 60 beats per minute, and a soft thyroid gland. Thyroid function tests with the commercial electrochemiluminescence immunoassay Elecsys using cobas 8000 (Roche Diagnostics GmbH, Basel, Switzerland) showed a markedly elevated Elecsys TSH (36.6 $\mu \mathrm{IU} / \mathrm{mL}$; reference interval: $0.20-4.50 \mu \mathrm{IU} / \mathrm{mL}$ ), whereas the Elecsys fT4 (1.22 ng/dL; reference interval: $0.80-1.60 \mathrm{ng} / \mathrm{dL}$ ) and Elecsys fT3 (2.8 pg/mL; reference interval: 2.2$4.3 \mathrm{pg} / \mathrm{mL}$ ) were within the reference intervals. Elecsys anti-thyroid peroxidase antibodies and Elecsys antithyroglobulin antibodies were not elevated (Table 1, column B). Thyroid ultrasound showed a hypoechoic nodule with an irregular margin in the left thyroid gland, measuring $9.4 \mathrm{~mm} \times 8.0 \mathrm{~mm} \times 12.3 \mathrm{~mm}$. Papillary thyroid carcinoma was suspected on fine-needle aspiration biopsy cytology. However, since percutaneous coronary intervention for angina was planned within a month, he decided to consider thyroid surgery afterward, with regular conservative follow-up in the interim.

With respect to thyroid dysfunction, the patient had a habit of eating kelp, containing much iodine, and thyroid dysfunction due to dietary iodine excess was initially suspected. However, even after iodine restriction for a month, his thyroid function test results were the same as at his first visit (Elecsys TSH $31.4 \mu \mathrm{IU} / \mathrm{mL}$, Elecsys fT4 $1.21 \mathrm{ng} / \mathrm{dL}$, Elecsys fT3 $2.5 \mathrm{pg} / \mathrm{mL}$ ) (Table 1, column C). Therefore, these results suggested a false elevation of the TSH level.

First, TSH levels were reconfirmed on the other two measurement systems, and the values were compared. The commercial chemiluminescent immunoassay Architect TSH level using an Architect analyzer I1000SR (Abbott Japan, Tokyo, Japan) was 5.20 $\mu \mathrm{IU} / \mathrm{mL}$ (reference interval: $0.35-4.94 \mu \mathrm{IU} / \mathrm{mL}$ ), which was slightly elevated, although lower than the Elecsys TSH (Table 1, column C). Architect fT4 and fT3 levels were within the reference intervals, $0.96 \mathrm{ng} / \mathrm{dL} \quad(0.70$ $1.48 \mathrm{ng} / \mathrm{dL})$ and $2.93 \mathrm{pg} / \mathrm{mL}(1.71-3.71 \mathrm{pg} / \mathrm{mL})$, respectively. The commercial chemiluminescent enzyme immunoassay Lumipulse presto TSH, using a Lumipulse L2400 (FUJIREBIO Inc., Tokyo, Japan), also showed an elevated TSH level, $20 \mu \mathrm{IU} / \mathrm{mL}$ (reference interval: 0.746-4.118 $\mu \mathrm{IU} / \mathrm{mL}$ ) (Table 1). Although TSH levels showed a tendency to be elevated above the reference intervals across all assays, a difference depending on the measurement method suggested the existence of some interfering substance. Next, serial dilution of the patient's serum and precipitation tests were performed. On serial dilution of the patient's serum at 1:2, 1:5, and 1:10 dilutions, the TSH recovery rate did not change (Table 2). In addition, the TSH recovery rate did not show significant decreases after polyethylene glycol (PEG) and protein G precipitation tests (Table 3).

Table 1 Timeline of thyroid function test results and TSH measurements of the three different platforms

\begin{tabular}{|c|c|c|c|c|}
\hline Variables Timeline & $\begin{array}{c}\mathrm{A} \\
\text { One month before }\end{array}$ & $\begin{array}{c}\text { B } \\
\text { At first visit to our hospital }\end{array}$ & $\begin{array}{c}\mathrm{C} \\
\text { One month after }\end{array}$ & Reference interval \\
\hline TSH $(\mu \mathrm{IU} / \mathrm{mL})$ & 40.0 & - & - & n. a. \\
\hline free $\mathrm{T} 3(\mathrm{pg} / \mathrm{mL})$ & 2.66 & - & - & n. a. \\
\hline free T4 (ng/dL) & 1.33 & - & - & n. a. \\
\hline Elecsys TSH $(\mu \mathrm{IU} / \mathrm{mL})$ & - & 36.6 & 31.4 & $0.2-4.5$ \\
\hline Elecsys free $\mathrm{T} 3(\mathrm{pg} / \mathrm{mL})$ & - & 2.8 & 2.5 & $2.2-4.3$ \\
\hline Elecsys free T4 (ng/dL) & - & 1.22 & 1.21 & $0.8-1.6$ \\
\hline Elecsys TgAb (IU/mL) & - & 10.7 & - & $\leq 40$ \\
\hline Elecsys TPOAb (IU/mL) & - & $<9.0$ & - & $\leq 28$ \\
\hline Architect TSH $(\mu \mathrm{IU} / \mathrm{mL})$ & - & - & 5.2 & $0.35-4.94$ \\
\hline Architect free T3 $(\mathrm{pg} / \mathrm{mL})$ & - & - & 2.93 & $1.71-3.71$ \\
\hline Architect free T4 (ng/dL) & - & - & 0.96 & $0.7-1.48$ \\
\hline Lumipulse presto TSH $(\mu \mathrm{IU} / \mathrm{mL})$ & - & - & 20.0 & $0.746-4.118$ \\
\hline
\end{tabular}

$\mathrm{TgAb}$, antithyroglobulin antibody; TPOAb, antithyroid peroxidase antibody; n.a., not available. 
Therefore, IgG-bound macro-TSH was ruled out. Gel filtration chromatography with a $\mathrm{pH} 7.2$ elution buffer was subsequently used to compare the patient's serum (Fig. 1A) with control serum (Fig. 1B). A fast elution time of about 25 minutes, showing a larger size molecule than IgA, suggested the presence of IgA-bound macroTSH. Gel filtration chromatography with an acid elution buffer (pH 3.0) can dissociate the antigen-antibody complex. The TSH peak of the patient's serum changed from a 25-minute elution time ( $\mathrm{pH}$ 7.2) to a typical 31.5minute elution time ( $\mathrm{pH} 3.0)$, indicating that immunoglobulin bound to TSH dissociated under the acid elution buffer (pH 3.0) (Fig. 2). Finally, to confirm the isotype of the immunoglobulin binding to TSH, a Jacalin precipitation test was performed (Table 3). Jacalin is an alpha-Dgalactose-binding lectin protein that can specifically bind to human IgA1 and secretory IgA1 [9]. After precipitation with Jacalin, the TSH recovery rate was reduced to $20 \%$, and the TSH level decreased from $30.7 \mu \mathrm{IU} / \mathrm{mL}$ to $2.01 \mu \mathrm{IU} / \mathrm{mL}$, within the reference interval. Thus, macroTSH due to IgA-bound TSH was confirmed. Since the

Table 2 TSH concentrations of the patient's serum in the dilution test

\begin{tabular}{lcc}
\hline & $\begin{array}{c}\text { TSH concentration } \\
(\mu \mathrm{IU} / \mathrm{mL})\end{array}$ & $\begin{array}{c}\text { Recovery rate } \\
(\%)\end{array}$ \\
\hline Undiluted solution & 30.7 & 100 \\
2-fold dilution & 30.8 & 100 \\
5-fold dilution & 32.3 & 105 \\
10-fold dilution & 33.5 & 109 \\
\hline
\end{tabular}

patient's thyroid function was determined to be within the reference interval, thyroid hormone replacement therapy was not initiated, and the patient was followed without levothyroxine.

\section{Discussion}

The first case of a macro-TSH consisting of IgAbound TSH was reported. In a search of the literature, no reports of IgA-bound macro-TSH were identified. In the present case, the following extremely important points were noted: although asymptomatic subclinical hypothyroidism was initially suspected, false TSH elevation due to IgA-bound macro-TSH was not overlooked, and accurate diagnosis avoided unnecessary thyroid hormone replacement therapy.

Subclinical hypothyroidism, a condition in which the TSH level is elevated and fT3 and fT4 levels are in the reference intervals, is a common clinical entity that occurs in $4-20 \%$ of the adult population $[1,10,11]$. Indications for treatment should be appropriately determined based on TSH levels (usually $10 \mu \mathrm{IU} / \mathrm{mL}$ or higher) and patient backgrounds, such as pregnant women, elderly persons, and patients with dyslipidemia [12-14]. In addition, the following cases that do not require treatment should be noted: transient thyroid dysfunction or, in rare cases, the false elevation of serum TSH levels due to measurement interference [15]. TSH levels should be reassessed after several months to rule out transient elevations due to painless thyroiditis or excessive iodine intake. In the present patient, thyroid dysfunction due to excessive iodine intake was highly suspected. However,

Table 3 TSH measurements of the three different precipitation tests with polyethylene glycol (PEG), protein G, and Jacalin

\begin{tabular}{|c|c|c|c|c|c|c|c|c|c|}
\hline & \multicolumn{3}{|c|}{ PEG precipitation } & \multicolumn{3}{|c|}{ Protein $G$ precipitation } & \multicolumn{3}{|c|}{ Jacalin precipitation } \\
\hline & \multicolumn{2}{|c|}{$\begin{array}{l}\text { TSH concentration } \\
(\mu \mathrm{IU} / \mathrm{mL})\end{array}$} & \multirow{2}{*}{$\begin{array}{c}\text { Recovery } \\
\text { rate }(\%)\end{array}$} & \multicolumn{2}{|c|}{$\begin{array}{l}\text { TSH concentration } \\
(\mu \mathrm{IU} / \mathrm{mL})\end{array}$} & \multirow{2}{*}{$\begin{array}{c}\text { Recovery } \\
\text { rate }(\%)\end{array}$} & \multicolumn{2}{|c|}{$\begin{array}{c}\text { TSH concentration } \\
(\mu \mathrm{IU} / \mathrm{mL})\end{array}$} & \multirow{2}{*}{$\begin{array}{l}\text { Recovery } \\
\text { rate }(\%)\end{array}$} \\
\hline & Before & After & & Before & After & & Before & After & \\
\hline $\begin{array}{l}\text { Patient's } \\
\text { serum }\end{array}$ & 30.7 & 11.3 & 74 & 30.7 & 17.2 & 112 & 30.7 & 2.01 & 20 \\
\hline $\begin{array}{l}\text { Control } \\
\text { serum }\end{array}$ & 3.64 & 1.39 & 76 & 3.64 & 1.75 & 96 & 3.64 & 1.15 & 95 \\
\hline
\end{tabular}

The Jacalin [9] precipitation test was performed after gel filtration chromatography.

The formula for calculating the recovery rate of the PEG and protein G precipitation tests is:

Recovery $(\%)=\frac{\text { twice the value measured after the addition of PEG or protein } G}{\text { the value measured before the addition of PEG or protein } G} \times 100$

The formula for calculating the recovery rate of the Jacalin precipitation test is:

Recovery $(\%)=\frac{\text { three times the value measured after the addition of Jacalin }}{\text { the value measured before the addition of Jacalin }} \times 100$

Due to the limited amount of protein $\mathrm{G}$ and Jacalin bound to agarose, the amount of IgG and IgA that can be bound to protein $\mathrm{G}$ agarose and Jacalin-bound agarose per fixed volume was examined. The volume that can bind a sufficient amount of serum IgG and IgA concentrations were protein G-bound agarose:serum $=1: 1$ and Jacalin-bound agarose:serum $=2: 1$, respectively. Therefore, the formula used a correction value of 2-fold for protein $\mathrm{G}$ and 3-fold for Jacalin. 
A

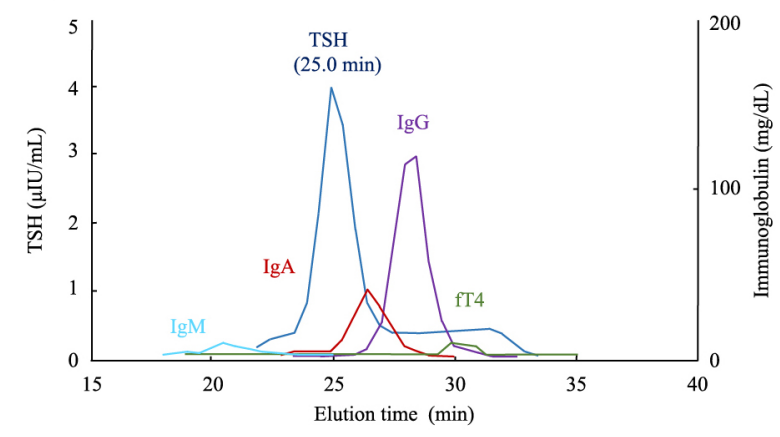

B

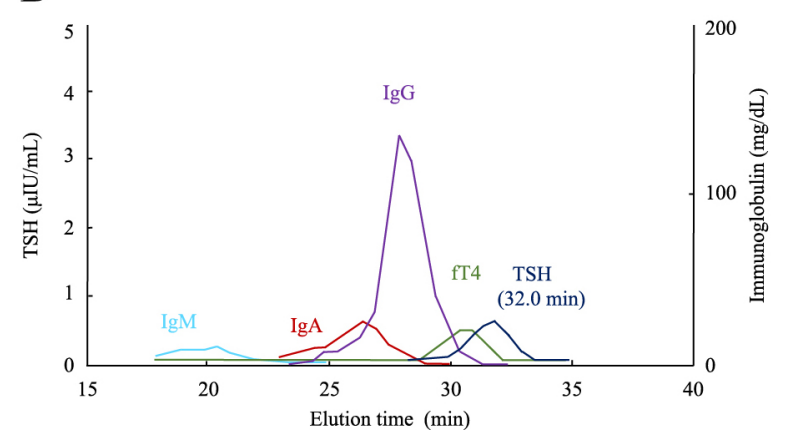

Fig. 1 Gel filtration chromatogram of the patient's serum and control serum.

A. Peaks of TSH, IgG, IgM, and IgA using the patient's serum.

B. Peaks of TSH, IgG, IgM, and IgA using control serum.

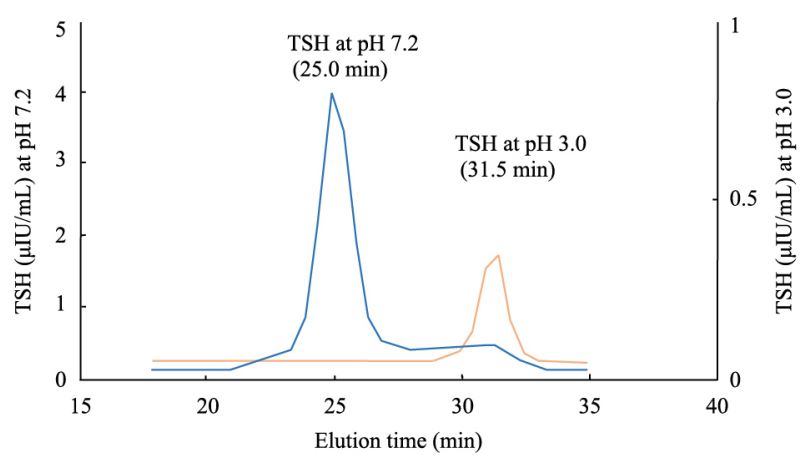

Fig. 2 Gel filtration chromatogram of the patient's serum using an acid elution buffer ( $\mathrm{pH} 3.0)$

the patient's TSH levels did not improve after iodine restriction. Finally, false elevation due to IgA-bound macro-TSH was identified. If macro-TSH was not diagnosed and the patient was initiated on levothyroxine, there would be a risk of cardiac events, including angina pectoris, heart failure, and atrial fibrillation, due to exogenous thyrotoxicosis [16]. This was especially important because the patient had a history of ischemic heart disease. Thus, the diagnosis of subclinical hypothyroidism should be made with caution.

In the 1980s, the accuracy of TSH measurements was improved by the shift from radioimmunoassay to enzyme-linked immunosorbent assay (ELISA), electrochemiluminescence immunoassay (ECLIA), and chemiluminescent immunoassay (CLIA) methods. In these methods, the monoclonal antibody is immobilized on the microplate well, and the TSH level is measured by the specific antibody/antigen reaction. In a one-step assay, the antigen-antibody reaction with a secondary antibody is performed on a plate, and, in a two-step assay, a secondary antibody is added following washing after an antigen-antibody reaction on a plate. The characteristics differ depending on the platform used, and macro-TSH is recognized at various levels [17]. The Architect TSH, a two-step assay, has the lowest reactivity to macro-TSH and the lowest degree of false elevation. Similarly, in the present patient, the Architect TSH level was the lowest. According to Hattori et al., in $40 \%$ of serum samples of macro-TSH, the TSH values were in the reference interval when using the Architect Platform, but they remained high in $60 \%$. Currently, none of the commercially available TSH measurement platforms can completely exclude macro-TSH.

The clinical findings that suggest the presence of macro-TSH include lack of symptoms and a TSH level that is higher than "usual subclinical hypothyroidism" [8]. The TSH response may be poor, even if levothyroxine treatment is initiated [6]. When a mother has macro-TSH, the neonate presents with macro-TSH due to immunoglobulin transferred from the placenta and shows high TSH levels. However, the macro-TSH in these neonates does not produce clinical symptoms and the high TSH level disappears transiently (less than 8 months) [18-20]. When macro-TSH is suspected based on the clinical findings, and if TSH values vary depending on the measurement method, a dilution test, and PEG, protein $\mathrm{G}$, and/or protein A precipitation tests are considered. Gel filtration chromatography can be added if a precise evaluation is required.

The present patient did not show a linear increase in TSH recovery with serial dilution of his serum, nor a decrease in the TSH recovery rate on PEG and protein G precipitation testing. Protein $G$ precipitates almost all $\mathrm{IgG}$, and PEG precipitates almost all IgG and IgM, but only about $50 \%$ of $\operatorname{IgA}$. These precipitation tests could lead to false-negative results for IgA-bound macro-TSH $[21,22]$. Therefore, the dilution test or PEG and protein $\mathrm{G}$ precipitation tests, which have been proposed so far, may have overlooked IgA-bound macro-TSH. As for 
macro-prolactin, a false-negative PEG precipitation test was reported in a patient with an IgA-bound macroprolactin [23]. With $\mathrm{pH} 7.2$ eluent, gel filtration chromatography of the patient's serum showed a TSH immunereactive molecule larger than $\operatorname{IgA}$, which suggested the presence of IgA-bound macro-TSH. Then, with $\mathrm{pH} 3.0$ eluent, this peak for a large molecule disappeared, and new IgA and normal TSH peaks appeared. Gel filtration chromatography helps detect macro-TSH with IgA if TSH recoveries do not decrease on PEG and protein G precipitation testing.

There are still some challenges associated with macroTSH. Hattori et al. reported that macro-TSH was present in $0.17 \%$ of infertile women, and they proposed that macro-TSH should be excluded in patients with subclinical hypothyroidism prior to hormone replacement therapy to avoid unnecessary levothyroxine treatment [24]. However, due to time and cost constraints, it can be difficult to confirm every case in routine clinical practice. It would be useful to develop a TSH assay platform that does not cross-react with macro-TSH in the future. Research into analysis by mass spectrometry is developing, and it is expected to be a highly accurate method of analyzing proteins, although the issue of cost has not yet been resolved [25]. Macro-TSH has been reported to lose its biological activity in vivo. The mechanism behind this loss of biological activity is still unclear, but one possibility is that TSH from the pituitary ridge (the pars tuberalis; PT) forms a macro-TSH complex with immunoglobulin or albumin [26]. Ikegami et al. reported that PT-specific glycosylation was likely to be responsible for the low biological activity of PT-TSH in the peripheral circulation [26]. It would be very interesting to clarify the role of macro-TSH in vivo.

In conclusion, if there is a discrepancy between thyroid function tests and clinical symptoms, and macroTSH is suspected, it is necessary to know that $\operatorname{IgA}$, as well as IgG, may be the cause of macro-TSH.

\section{Statement of Ethics}

Written, informed consent was obtained from the patient for the release of clinical details.

\section{Conflict of Interest Statement}

The authors have no conflicts of interest to declare.

\section{References}

1. Cooper DS, Biondi B (2012) Subclinical thyroid disease. Lancet 379: 1142-1154.

2. Kasagi K, Iwata M, Misaki T, Konishi J (2003) Effect of iodine restriction on thyroid function in patients with primary hypothyroidism. Thyroid 13: 561-567.

3. Tajiri J, Higashi K, Morita M, Umeda T, Sato T (1986) Studies of hypothyroidism in patients with high iodine intake. J Clin Endocrinol Metab 63: 412-417.

4. Favresse J, Burlacu MC, Maiter D, Gruson D (2018) Interferences with thyroid function immunoassays: clinical implications and detection algorithm. Endocr Rev 39: 830-850.

5. Fahie-Wilson MN, John R, Ellis AR (2005) Macroprolactin; high molecular mass forms of circulating prolactin. Ann Clin Biochem 42: 175-192.

6. Hattori N, Ishihara T, Yamagami K, Shimatsu A (2015) Macro TSH in patients with subclinical hypothyroidism. Clin Endocrinol (Oxf) 83: 923-930.

7. Loh TP, Kao SL, Halsall DJ, Toh SA, Chan E, et al. (2012) Macro-thyrotropin: a case report and review of literature. J Clin Endocrinol Metab 97: 1823-1828.

8. Ohba K, Maekawa M, Iwahara K, Suzuki Y, Matsushita A, et al. (2020) Abnormal thyroid hormone response to TRH in a case of macro-TSH and the cut-off value for screening cases of inappropriate TSH elevation. Endocr $J$ 67: 125-130.

9. Gregory RL, Rundegren J, Arnold RR (1987) Separation of human $\operatorname{IgA} 1$ and $\operatorname{IgA} 2$ using jacalin-agarose chromatography. J Immunol Methods 99: 101-106.

10. Canaris GJ, Manowitz NR, Mayor G, Ridgway EC (2000) The Colorado thyroid disease prevalence study. Arch Intern Med 160: 526-534.

11. Nakajima Y, Yamada M, Akuzawa M, Ishii S, Masamura Y, et al. (2013) Subclinical hypothyroidism and indices for metabolic syndrome in Japanese women: one-year follow-up study. J Clin Endocrinol Metab 98: 3280-3287.

12. Jonklaas J, Bianco AC, Bauer AJ, Burman KD, Cappola AR, et al. (2014) Guidelines for the treatment of hypothyroidism: prepared by the american thyroid association task force on thyroid hormone replacement. Thyroid 24: 1670-1751.

13. Sawka AM, Cappola AR, Peeters RP, Kopp PA, Bianco AC, et al. (2019) Patient context and thyrotropin levels are important when considering treatment of subclinical hypothyroidism. Thyroid 29: 1359-1363.

14. Taylor P, Bianco AC (2019) Urgent need for further research in subclinical hypothyroidism. Nat Rev Endocrinol 15: 503-504.

15. Ismail AA (2009) Thyroid stimulating hormone cut-off to define subclinical hypothyroidism. Ann Clin Biochem 46: 426.

16. Flynn RW, Bonellie SR, Jung RT, MacDonald TM, Morris $\mathrm{AD}$, et al. (2010) Serum thyroid-stimulating hormone concentration and morbidity from cardiovascular disease and 
fractures in patients on long-term thyroxine therapy. J Clin Endocrinol Metab 95: 186-193.

17. Hattori N, Ishihara T, Shimatsu A (2016) Variability in the detection of macro TSH in different immunoassay systems. Eur J Endocrinol 174: 9-15.

18. Rix M, Laurberg P, Porzig C, Kristensen SR (2011) Elevated thyroid-stimulating hormone level in a euthyroid neonate caused by macro thyrotropin-IgG complex. Acta Paediatr 100: e135-e137.

19. Karlsson FA, Dahlberg PA, Alm J, Larsson A, Felding I (1986) Maternal TSH-receptor antibodies and TSH antibodies in screening for congenital hypothyroidism. Acta Paediatr Scand 75: 756-761.

20. Lazarus JH, John R, Ginsberg J, Hughes IA, Shewring G, et al. (1983) Transient neonatal hyperthyrotrophinaemia: a serum abnormality due to transplacentally acquired antibody to thyroid stimulating hormone. Br Med J (Clin Res Ed) 286: 592-594.

21. Sturgeon CM, Viljoen A (2011) Analytical error and interference in immunoassay: minimizing risk. Ann Clin
Biochem 48: 418-432.

22. Jassam NF, Paterson A, Lippiatt C, Barth JH (2009) Macroprolactin on the Advia Centaur: experience with 409 patients over a three-year period. Ann Clin Biochem 46: 501-504.

23. Kilvington F RA, Kavanagh L, Smith T, Fahie-Wilson M (2006) False negative PEG precipitation test in a case of hyperprolactinaemia with an IgA macroprolactin. Ann Clin Biochem 43 Suppl: 35.

24. Hattori N, Aisaka K, Chihara K, Shimatsu A (2018) Current thyrotropin immunoassays recognize macrothyrotropin leading to hyperthyrotropinemia in females of reproductive age. Thyroid 28: 1252-1260.

25. Anderson NL (2010) The clinical plasma proteome: a survey of clinical assays for proteins in plasma and serum. Clin Chem 56: 177-185.

26. Ikegami K, Liao XH, Hoshino $\mathrm{Y}$, Ono $\mathrm{H}$, Ota $\mathrm{W}$, et al. (2014) Tissue-specific posttranslational modification allows functional targeting of thyrotropin. Cell Rep 9: 801-810. 